\title{
XLII. An accurate statement of facts relative to a stroke of lightning, which happened on the 13th of April 1832
}

\section{Benjamin Boddington Esq.}

To cite this article: Benjamin Boddington Esq. (1832) XLII. An accurate statement of facts relative to a stroke of lightning, which happened on the 13th of April 1832, Philosophical Magazine Series 3, 1:3, 191-197, DOI: 10.1080/14786443208647871

To link to this article: http://dx.doi.org/10.1080/14786443208647871

曲 Published online: 01 Jun 2009.

Submit your article to this journal $[\pi$

Џll Article views: 3

Q View related articles $\sqsubset$ 
my brother, Mr. Thomas Blackwall; and perceive that there is not only a great disparity in size, and a wide dissimilarity in colour between the two species, (circumstances which might be supposed to arise from a difference in age merely,) but that they likewise differ very decidedly in figure and structure; thus clearly establishing the fact that they are specifically distinct. The former has the mandibles much less prominent, and the abdomen more nearly cylindrical than the latter; its tarsi also are destitute of brushes, with which instruments those of Dysdera erythrina are provided.

In adding another species to the solitary one at present constituting the genus Dysdera of M. Latreille, I avail myself of the opportunity to confer upon it the name of that illustrious naturalist, whose important researches have contributed so largely to the advancement of arachnology.

Crumpsall Hall, Aug. 10, 1832.

XLII. An accurate Statement of Facts relative to a Stroke of Lightning, which happened on the 13th of April 1832. By Benjamin Bodington, Esq.*

N Friday, the 13th of April 1832, Mr. and Mrs. Thomas F. Boddington, having partaken of some refreshment at Tenbury, placed the servants inside their post-chariot, and mounted themselves the barouche seat behind, that they might enjoy the scenery on the road to Bromyard, through the ramifications of the Abberley Hills. It was about half-past three when they left, the sun shining, and the sky serene; but before they had proceeded far, they observed a dark and singular-looking cloud to arise, nearly in the direction of their route, and at the end of about three miles and a half a few drops of rain began to fall : they debated whether they should get inside the carriage, but agreed that the storm (for such it appeared to be) was passing off to the right, and that it would in all probability be only a slight shower, as the cloud in their immediate vicinity, though peculiarly dark and angrylooking, was of very small dimensions; - at this time a clap of distant thunder was heard, but no lightning seen. Mr. Boddington put up an umbrella ; but perceiving that it was an old one, somewhat torn, (belonging to one of the servants,) he gave it to his wife to hold over her bonnet, while he put up another ; when in the act of extending the latter, a flash of lightning struck them both senseless, threw the horses on the ground, and cast the post-boy to a considerable distance. The ser-

* Communicated by Mr. Faraday. 
vants inside were untouched, and indeed unconscious of the real nature of the accident: the man says that he heard no previous thunder, but that a vivid flash of lightning, proceeding as he thought from the side of the road next to which he sat, was accompanied by an instantaneous report, like the discharge of a highly loaded blunderbuss; and he concluded that some robber, or other mischievous person, had shot the horses. He acknowledges that he was so panic-struck that for a few seconds he sat still; but on recovering from the momentary alarm, he let down the side glass and looked out to see whether his master and mistress were safe, - he was shocked to perceive the head of the former hanging over the seat, and apparently lifeless: he immediately jumped from the carriage, and ascending the steps behind, raised his master's head, and found that his clothes were on fire; his mistress was standing up, tearing off her bonnet and shawls. Her account of the matter is this : - that she neither saw the flash nor heard the thunder, but her first consciousness was the feeling of suffocation, and that she was pulling off her things to obtain air; she felt, however; that they had been struck by lightning, and immediately commenced assisting the servant to extinguish the fire that was stitl consuming the dress of her husband.

The passage of the electric fluid, as connected with Mrs. Boddington, was most distinctly to be traced: it struck the umbrella she had in her hand;-it was, as I before stated, an old one, made of cotton, and had lost the ferule that is usually placed at the end of the stick; so that there was no point to attract the spark : it was literally shivered to pieces, both the springs in the handle forced out, the wires that extended the whalebone broken, and the cotton covering rent into a thousand shreds. From the wires of the umbrella the fluid passed to the wire that was attached to the edge of her bonnet, the cotton-thread that was twisted round that wire marking the place of entrance over the left eye, by its being burnt off from that spot all round the right side, crossing the back of the head and down into the neck above the left shoulder; the hair that caine in contact with it was also singed : it here made a hole through the handkerchief that was round her throat, and zigzagged along the skin of her neck to the steel busk of her stays, leaving a painful but not deep wound, and also affecting the hearing of the left ear. It entered the external surface of the busk:- this is clearly proved by the brown paper case in which it was inclosed being perforated on the outside, and the busk itself fused for about a quarter of an inch on the upper surface, presenting a blistered appearance. Its passage down the busk could not be traced in any way; there was no mark 
whatever on the steel, nor was the paper that covered it discoloured or altered in the slightest degree; its exit at the bottom, however, was as clearly indicated as its entrance at the top; the steel was fused in the same manner, and the paper was perforated in the same way, but on the opposite side.

The magnetic properties acquired by the busk are curious. Both ends attract strongly the south pole of the needle, the upper part for some considerable way down; it then begins to lose power over the south pole, and the point of northern attraction is at about one third of the length of the busk from the bottom; so that by far the greatest portion of the whole has acquired southern attraction. Perhaps it will be best explained by the following sketch of the inside face of the steel, which is fourteen inches and a half long, by one inch and three-eighths wide.

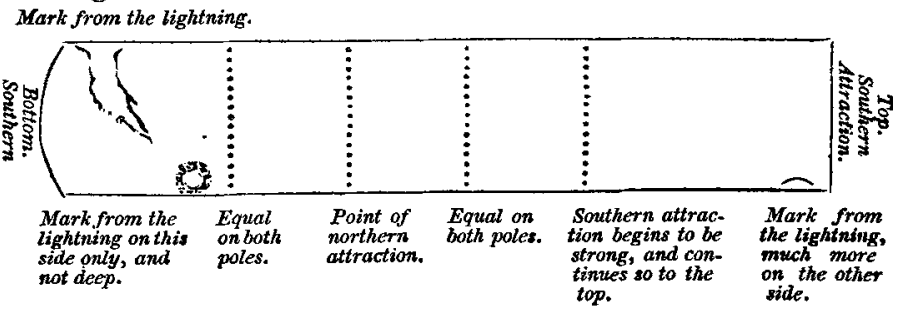

There were marks of burning on the gown and petticoat above the steel; and the inside of the stays, and all the garments under the stays, were pierced by the passage of the fluid to her thighs, where it made wounds on both; but that on the left so deep, and so near the femoral artery, that the astonishment is, that she escaped with life;--even as it was, the hemorrhage was very great. Every article on which she sat was perforated to the cushion of the seat, the cloth of which was torn in a much more extensive way than the clothes: in most cases they were pierced by a hole not exceeding the size of half an inch in diameter, and even where the rents were larger they did not extend beyond an inch or two in any direction : but it is worthy of observation, that every article the electric fluid passed through had a singed appearance at the edges (and had a sulphureous smell, as I was informed by those who inspected them immediately after the accident: by the time I reached Tenbury, all trace of this smell had vanished). No ignition, however, took place beyond what occurred at the moment of its passage, notwithstanding the inflammable nature of most of the articles; nor did any of Mrs. Boddington's wounds present the appearance of burns. The cushion of the barouche seat was stuffed with curled horse-hair, through which the Third Series. Vol. 1. No. 3. Sept. 1832. 
stream must have passed, though no sign to indicate its passage was visible; the cloth edge of the cushion, however, immediately behind where Mrs. Boddington sat, was torn outwards, and the leather that covered the iron forced off in the same spot, clearly marking its egress at this place.

As this same iron also received the charge that struck $\mathrm{Mr}$. Boddington, I shall now state the effects of the lightning on him, before I trace its further progress. When first discovered by his servant, he was, as I have said, insensible, and he remained in that state for about the space of ten minutes, when he revived sufficiently to inquire where he was, but relates that he was perfectly unconscious of what had occurred; that he felt his eyesight affected, and pain all over him, but knew not from what cause these sensations arose. The umbrella in this case also was the conductor; it was made of silk, and was but little damaged, a small portion of the upper part only being torn where it joins the stick, and none of the springs or wires being displaced. The main force of the shock, however, appears to have passed down the handle to his left arm, though a portion of it made a hole through the brim of his hat, and burnt off all the hair that was below it, together with the eyebrows and eyelashes; the fragments of the burnt parts falling into the eyes deprived him neariy of sight for two or three days, but the eyes were not otherwise injured. The electric stream shattered the left hand, fused the gold shirt-buttons, and tore the clothes in a most extraordinary manner, forcing parts of them together with the buttons to a considerable distance; and a deep wound was inflicted under its position on the wrist. The arm was laid bare to the elbow, which is presumed to have been at the moment very near his left waistcoat-pocket, in which there was a knife; this also was forced from its situation, and found on the ground; a severe wound was made on his body, and every article of dress torn away as if it had been done by gunpowder. From the knife it passed to the iron of the seat, wounding his back, and setting fire to his clothes in its passage. Another portion descended to the right arm, which had hold of the lower part of the stick of the umbrella; was attracted by the sleeve-button, where it made a wound, but slight as compared to that on the left, passed down the arm (which it merely discoloured, and broke the skin of in two small places,) to a gold pencil-case in the right waistcoat-pocket. The great-coat he had on was an old navy watch-coat, commonly called a pea-jacket, and of great thickness; this was torn to pieces, and the coat immediately above the waistcoat-pocket much rent; but the waistcoat itself was merely perforated; on the external part, 
where the discharge entered by a hole about the size of a pea, and on the inside by a similar hole at the other extremity of the pencil-case, where it passed out, setting fire to his trowsers and drawers, and inflicting a deep wound round his back, the whole of which was literally flayed.

A very striking difference was observable in the wounds of Mr. and Mrs. Boddington : her's, as I before stated, were fractures of the flesh; his, on the contrary, whether deep or shallow, were all of them burns, and had a white and blistered appearance. The accumulation of force which the electricity acquired at this place deserves particular attention. I have observed that the shock on the right arm was nothing as compared to that on the left; the shirt-button was unchanged, and unmoved from its position, and the passage of the fluid down the arm barely indicated; yet when it arrived at the pencil-case, the amount of its intensity was such as to melt one end of it, and displace a cornelian seal at the other extremity, forcing it, I suppose, to some distance, as it has never since been found, though it was carefully sought after. It should seem that this accumulation of strength must have been derived either from the portion that passed over Mrs. Boddington, or from union with that which went down the left arm; in either case it appears to have been strangely diverted from its original course. The whole shock was now collected in the iron that formed the back of the barouche seat; the leather attached to it was torn off, and the iron itself broken in two, immediately opposite the spring, and the ends of the fractured parts bent forwards so as nearly to touch it: by this conveyance it is supposed to have diffused itself over the whole of the under carriage, and to have passed to the earth by the tires of the wheels, four holes being made in the road at the points they tonched at the moment of the shock, though the carriage was not standing in them at the time it stopped. The post-chariot was a new one, and the only injury it received, was the fracture and derangement of the barouche seat, as already stated, the removal of the japan in a line along the bulge behind, and the breaking of the pole; the latter circumstance I conceive to have arisen, solely, from the fall of the horses, and to have been quite independent of the passage of the electric fluid. The horse the postilion rode was found to be dead; the other was evidently panic-struck, but unhurt, as he rose as soon as the harness was cleared from him; and though in a profuse sweat and trembling, he soon recovered, and not only was rode back for assistance, but returned again in the chaise that conveyed the poor sufferers to Tenbury, where they were detained at the inn for a month before it was thought safe to remove them. $2 \mathrm{C} 2$ 
$196 \mathrm{Mr}$. B. Boddington on the Effects of a Stroke of Lightning.

On inspecting the dead horse no wound was visible, nor any apparent cause for his death; the brass front of the bridle was observed to be indented inwards, as if struck with a hammer; and when he was skinned, a corresponding mark was found on the bone of the head; and from that spot to the termination of the spine, the flesh was quite black and putrid for about the width of three inches, and there were diverging marks of the same nature on each side of the head, passing under the throat, and similar but much wider ones on the flanks. The post-boy was thrown some yards off, but this I conceive to have been by the spring of the horse when he was struck dead; and that spring doubtless jerked the carriage beyond the holes where the lightning had passed into the earth. The boy was shaken by his fall, but in other respects perfectly unhurt. I inspected the spot nearly three weeks after the accident happened, found it was elevated ground, but by no means the summit of the surrounding country; on the contrary, there were many higher hills in the neighbourhood: the road itself was so much hollowed out, that the banks must have been nearly equal to the height of the carriage; in a field to the right, within a few yards of the hedge, and exactly opposite to where the shock took place, was a very high peartree,-it however bore no trace of injury. The carriage appears to have been passing close to that side of the bank, as the holes I have before alluded to were still perfectly visible; indeed, the two to the right had undergone very little change, as they were nearly off the road; they were about fifteen inches in diameter, perfectly round, and nearly as deep as they were wide, the stones appearing to have been thrown out as if done by a miner's blast.

The collateral facts must now be mentioned. The landlord of the inn at Tenbury informed me that he was sitting in his parlour, talking to another person, when he saw the flash of lightning that must have caused the accident; he observed to his companion, that he had never before seen so singular a flash, as it appeared to divide into four parts when it came within about thirty yards of the earth; - this statement was confirmed by the person who was with him. It should seem, therefore, that they were not struck by a single discharge of electric matter; but were enveloped in a mass of electricity; and this is the more probable, from the traces of the different strokes being so distinct, and yet taking such opposite directions: the fluid seems to have pervaded the whole atmosphere, as many things were magnetized that were not in the line of any of the tracks that could be traced. For instance, Mr. Boddington's watch was in his fob, and quite out of the line described by either of the shocks that passed over him: 
after the accident, it was found necessary to send it to a watchmaker, and when taken to pieces, parts of it were discovered to be highly magnetized, the balance-wheel in particular. This was shown to Mr. Faraday, when at Oxford, who set it afloat on a cork, and found the poles to be so well defined, that I have since had it mounted as a compass. Two pair of scissars also that were in Mrs. Boddington's work-box inside the carriage, were by mere accident, two months after the event, discovered to be magnetic.

I certainly now very much regret that more minute researches were not made at the time as to these facts: but whoever has watched over the sick-bed of a beloved son, with but faint hopes of his recovery, will not be surprised that philosophical investigations were all absorbed in the deeper interest of the affections.

Badger Hall, July 16, 1832.

XLIII. Further Experiments with a new Registe-Pyrometer for Measuring the Expansion of Solids. By J. Frederick Daniele, Esq. F.R.S. Professor of Chemistry in King's College, London.*

I my former communication on a new Register-pyrometer, which has been honoured with a place in the Philosophical Transactions for 1830 , I stated that I hoped, at some future period, to be able to lay before the Society the results of some experiments upon the dilatation of metals to their melting points; and I now purpose to redeem this pledge.

My previous observations upon the subject of expansion, were directed chiefly to the object of establishing what degree of confidence might be reposed in the instrument as a measure of temperature; and I was able, I trust, to exhibit such an accordance between the measures which it had afforded and those of the best experimenters, long previously obtained with various metals to the boiling point of water, as fully to establish its sufficient accuracy. The comparison however which I most relied upon, was with the experiments of MM. Dulong and Petit, upon the expansion of platinum and iron to the high temperature of $572^{\circ} \mathrm{Fahr}$.; and as this is a point of fundamental importance, I shall still further strengthen it by a comparison with the results obtained by the same distin-

* From the Philosophical Transactions for 1831, Part ii.: this paper was read before the Royal Society, on the 16th of June in that year.

Prof. Daniell's former communication on the same subject will be found in the Phil. Mag. and Annals, vol, x. beginning at p. 191 . 